\title{
Sleep Apnea in Caucasian and Asian Climacteric Women
}

\author{
Irina Madaeva, $\mathrm{PhD}, \mathrm{ScD}^{*}$; Natalya Semenova, $\mathrm{PhD}$; Erdem Ukhinov, MD; \\ Lubov Kolesnikova, Academician of the RAS \\ Scientific Centre for Family Health and Human Reproduction Problems \\ Irkutsk, the Russian Federation
}

\begin{abstract}
The aim of our study was to define the structure of sleep in Caucasian and Asian peri- and postmenopausal women with sleep apnea.

Materials and Methods: Two hundred and forty-seven menopausal women between 45 and 60 years of age participated in this study. The participants were divided into 2 ethnic groups, taking into account the genealogy (the representatives having in two generations of parents of one ethnic group) and self-identification, taking into account phenotype elements. Caucasians were represented by the Russian ethnic group $(n=115)$ and Asians by the Buryat ethnic group $(n=132)$. The study included the collection of anamnestic data, physical examinations, clinical (Berlin questionnaire, general medical examination, gynecological examination, polysomnographic monitoring according to American Academy of Sleep Medicine recommendations), and biochemical laboratory methods.

Results: Sleep complaints, such as difficulty falling asleep, frequent night awakenings (more than 2 times), difficulties of morning awakening or problems waking up too early, were increased in perimenopausal Caucasian women. We found ethnic differences in a greater frequency of complaints in Caucasian women, but Asian women also showed a tendency to increased complaints about poor sleep. Polysomnographic monitoring revealed that OSA was more common in Asian postmenopausal women than in Caucasians. However, in structure of sleep we have not seen distinctions.

Conclusion: For improving the quality of life, it is necessary not only to pay attention to menopausal problems, but also to solve the sleep problems associated with various strategies, both age management and lifestyle. (International Journal of Biomedicine. 2018;8(4):296-300.)
\end{abstract}

Key Words: climacteric women $\bullet$ sleep apnea $\bullet$ Caucasians $\bullet$ Asians $\bullet$ sleep structure

\section{Abbreviations}

BMI, body mass index; EEC, endometrial echo-complex; FSH, follicle-stimulating hormone; LH, luteinizing hormone; OSA, obstructive sleep apnea; QL, quality of life; REM, rapid-eye-movement; SD, sleep disorders; SDB, sleep-disordered breathing.

\section{Introduction}

Earlier, we studied various metabolic aspects of sleep disturbances in the male and female population. ${ }^{(1,2)}$ It is known that menopausal women experience various sleep-related disorders. ${ }^{(3-6)}$ Menopause is characterized by a decrease in the production of female sex hormones, most specifically estrogen. According to the US National Library of Medicine, ${ }^{(7)}$ about

*Corresponding author: Irina M. Madaeva, PhD, ScD. Chief of the Somnological Center at Scientific Centre for Family Health and Human Reproduction Problems. Irkutsk, Russia. E-mail: nightchild@mail.ru
$16 \%$ to $42 \%$ of premenopausal women and $35 \%$ to $60 \%$ of postmenopausal women have sleep disorders (SD). There are many scientific data on sleep-related symptoms in menopausal women. ${ }^{(8-10)}$ However, in the small number of studies of sleeprelated symptoms there are reports of certain ethnic differences in sleep-related those symptoms experienced in the menopausal transition. These studies found no difference in sleep symptoms between black and white participants, but in a cross-sectional analysis among an elderly community cohort, performed by Mezick et al., ${ }^{(1)}$ snoring, sleepiness and long sleep duration were more common in Hispanics. The SWAN study (2008), which included Caucasian, African and Chinese menopausal women, described ethnic differences for staying asleep and 
early morning awakening. Further studies have evaluated the polysomnographic monitoring indicators, which also have revealed differences in the sleep pattern, showing that African women experience greater sleep latency, shorter total sleep time and lower sleep efficiency than do other ethnic groups. However, there are no studies of SD in Caucasian and Asian peri- and postmenopausal women in Russia. Some researchers have shown that Asian men (Chinese) had the highest rates of SDB among the 3 major ethnic groups. ${ }^{(12)}$

There are many nationalities living in East Siberia near Lake Baikal. The largest part of Asian representatives are Buryats, and of Caucasian representatives are Russians. The aim of our study was to define the structure of sleep in Caucasian and Asian peri- and postmenopausal women with sleep apnea.

\section{Materials and Methods}

The study was approved by the Scientific Center of Family Health Problems and Human Reproduction Ethics Committee. Written informed consent was obtained from each patient.

Two hundred and forty-seven menopausal women between 45 and 60 years of age participated in this study between February 2016 and February 2018. The participants were divided into 2 ethnic groups, taking into account the genealogy (the representatives having in two generations of parents of one ethnic group) and self-identification, taking into account phenotype elements. Caucasians were represented by the Russian ethnic group $(\mathrm{n}=115)$ and Asians by the Buryat ethnic group $(\mathrm{n}=132)$.

Inclusion criteria were amenorrhea $\geq 12$ months; a basal level of $\mathrm{FSH}>20 \mathrm{iU} / \mathrm{ml}, \mathrm{LH} / \mathrm{FSH}$ ratio $<1$; ultrasounds criteria: (1) thin non-functional endometrium, the EEC measured $<5 \mathrm{~mm}$; (2) the loss of ovarian reserve.

Exclusion criteria were exacerbation of chronic diseases; hormone replacement therapy; surgical menopause; the presence of chronic sleep disorders in a case history (insomnia, parasomnia, hypersomnia, OSA syndrome); the use of hypnotic pills in the previous two weeks; shift work.

Most of the Caucasian women were recruited for study in Irkutsk and Asian women in Ulan-Ude (Byryat Republic). The study included the collection of anamnestic data, physical examinations, clinical (questionnaire, general medical examination, gynecological examination, polysomnographic monitoring), and biochemical laboratory methods. All participants were asked to take part in the follow-up questionnaire.

The questionnaire was available in Russian because it is the major language spoken in East Siberia. The questionnaire included self-reported sleep symptoms and the menopausal status. Menopausal status was assessed by self-reports based on the Modified Menopausal Index (MMI).

The Berlin questionnaire for OSA is one of the most commonly used. It combines risk factors, such as snoring, sleepiness, obesity and hypertension, to reliably predict OSA syndrome. According to this questionnaire, there are 2 levels of severity of the risk: a high risk (if there are 2 or more categories where the score is positive) and a low risk (if there is only 1 or no categories where the score is positive). ${ }^{(13-16)}$
The polysomnographic monitoring was carried out in a specially equipped room, which was as close as possible to the conditions of a bedroom, using the GRASSTELEFACTOR Twin PSG(Comet) system with an As 40 amplifier with the SPM-1(USA) integrated sleep module, according to the standard methodology. We evaluated overnight 16-channel polysomnography with 2 electroencephalograms $(\mathrm{C} 4, \mathrm{C} 3, \mathrm{O} 1, \mathrm{O} 2), 2$ electrooculograms (ROC, LOC) and 2 electromyogram channels; oral/nasal airflow by thermistor; respiratory effort via conductance belts on chest and abdomen; snoring sounds via microphone; oxygen saturation via pulse oximeter. Each 30 -sec epoch was manually scored using standard scoring criteria supplemented by apnea-hypopnea criteria, according to American Academy of Sleep Medicine recommendations. ${ }^{(17)}$

Statistical analysis was performed using STATISTICA 6.1 software (Stat-Soft Inc., USA). Baseline characteristics were summarized as frequencies and percentages for categorical variables and as mean \pm standard deviation for continuous variables. Differences of continuous variables departing from the normal distribution were tested by the Mann-Whitney U-test. The frequencies of categorical variables were compared using Pearson $\chi 2$ or Fisher's exact test, when appropriate. A probability value of $P \leq 0.05$ was considered statistically significant.

\section{Results}

Results of sleep complaints and comparative analysis of sleep characteristics of Caucasian and Asian menopausal women are presented in Table 1. Sleep complaints, such as difficulty falling asleep, frequent night awakenings (more than 2 times), difficulties of morning awakening or problems waking up too early, were increased in perimenopausal Caucasian women. We found ethnic differences in a greater frequency of complaints in Caucasian women, but Asian women also showed a tendency to increased complaints about poor sleep. However, results of the Berlin questionnaire showed a high risk of having OSA syndrome in Asian postmenopausal women.

Basic physical characteristics of participants are summarized in Table 2. After the clinical-anamnestic method, the following stage of the research was polysomnographic monitoring in a sleep laboratory in participants with high and low risk of OSA syndrome. Results of polysomnographic characteristics in participants are presented in Table 3. OSA was more common in Asian postmenopausal women than in Caucasians. However, in structure of sleep we have not seen distinctions.

\section{Discussion}

Our study showed ethnic features of SD in menopausal women of 2 races living in East Siberia. Asian women selfreported frequent night awakenings and high risk of SDB, but more severe menopausal symptoms were found in White women compared to Asian women. It is known that a low level of female sex hormones can lead to SDB, which worsens QL. ${ }^{(18-20)}$ The differences in the course of menopause in women of different races has been demonstrated in many studies. ${ }^{(21-25)}$ 
Table 1.

Result of self-reported sleep symptoms in Caucasian and Asian menopausal women

\begin{tabular}{|c|c|c|c|c|c|}
\hline \multirow[b]{2}{*}{ Characteristics } & \multicolumn{2}{|c|}{ Caucasian women $(\mathrm{n}=115)$} & \multicolumn{2}{|c|}{ Asian women $(=132)$} & \multirow[b]{2}{*}{$P$-value } \\
\hline & $\begin{array}{l}\text { Perimenopausal } \\
\text { women }(\mathrm{n}=56)(1)\end{array}$ & $\begin{array}{l}\text { Postmenopausal } \\
\text { women }(n=59)(2)\end{array}$ & $\begin{array}{c}\text { Perimenopausal } \\
\text { women }(n=56)(3)\end{array}$ & $\begin{array}{l}\text { Postmenopausal } \\
\text { women }(n=76)(4)\end{array}$ & \\
\hline $\begin{array}{l}\text { Difficulty falling asleep (more than } \\
30 \text { minutes), } \mathrm{n}(\%)\end{array}$ & $39(69.6)$ & $32(54.2)$ & $29(51.8)$ & $46(60.5)$ & $P_{1-3}=0.05$ \\
\hline $\begin{array}{l}\text { Frequent night awakenings (more } \\
\text { than } 2 \text { times), } \mathrm{n}(\%)\end{array}$ & $15(26.8)$ & $37(62.7)$ & $27(48.2)$ & $40(52.6)$ & $\begin{array}{l}P_{1-2}=0.000 \\
P_{1}=0.019\end{array}$ \\
\hline $\begin{array}{l}\text { Difficulties of morning awakening } \\
\text { or problems waking up too early, } \\
\mathrm{n}(\%)\end{array}$ & $48(85.7)$ & $29(49.2)$ & $39(69.6)$ & $45(59.2)$ & $\mathrm{P}_{1-3}=0.041$ \\
\hline \multicolumn{6}{|c|}{ ESS (Epworth Sleep Scale) } \\
\hline $0-10, \mathrm{n}(\%)$ & $17(30.4)$ & $21(35.6)$ & $20(35.7)$ & $46(60.5)$ & $\begin{array}{l}\mathrm{P}_{2-4}=0.004 \\
\mathrm{P}_{3-4}<0.005\end{array}$ \\
\hline $10-24, \mathrm{n}(\%)$ & $39(69.6)$ & $38(64.4)$ & $36(64.3)$ & $30(39.5)$ & $\begin{array}{l}\mathrm{P}_{2-4}<0.01 \\
\mathrm{P}_{3-4}<0.005\end{array}$ \\
\hline \multicolumn{6}{|c|}{ Berlin questionnaire } \\
\hline Low risk $\mathrm{n}(\%)$ & $27(48.2)$ & $30(50.8)$ & $23(41.1)$ & $26(34.2)$ & $\mathrm{P}_{2-4}=0.05$ \\
\hline
\end{tabular}

Table 2.

Basic physical characteristics of Caucasian and Asian menopausal women

\begin{tabular}{|c|c|c|c|c|c|}
\hline Characteristics & \multicolumn{2}{|c|}{ Caucasian women $(n=115)$} & \multicolumn{2}{|c|}{ Asian women $(n=132)$} & $P$-value \\
\hline Age, yrs & $54.34 \pm 4.81$ & $53.25 \pm 5.18$ & $54.92 \pm 5.04$ & $54.1 \pm 4.32$ & \\
\hline $\begin{array}{l}\text { Place of residence, n (\%) } \\
\text { Irkutsk, n (\%) } \\
\text { Ulan-Ude, n }(\%) \\
\text { Other region }\end{array}$ & $\begin{array}{l}57(81.4) \\
9(12.8) \\
4(5.7) \\
\end{array}$ & $\begin{array}{c}39(86.7) \\
6(13.3) \\
- \\
\end{array}$ & $\begin{array}{c}11(12.5) \\
77(87.5) \\
- \\
\end{array}$ & $\begin{array}{c}6(13.6) \\
38(86.3) \\
- \\
\end{array}$ & \\
\hline $\begin{array}{l}\text { Menopausal status } \\
\text { Perimenopause, n (\%) } \\
\text { Postmenopause, n (\%) }\end{array}$ & $\begin{array}{c}37(52.8) \\
33(47.14)\end{array}$ & $\begin{array}{l}19(42.2) \\
26(57.8)\end{array}$ & $\begin{array}{l}33(37.5) \\
55(62.5)\end{array}$ & $\begin{array}{l}23(52.3) \\
21(47.7)\end{array}$ & $P_{1-3}=0.05$ \\
\hline \multicolumn{6}{|c|}{ MMI } \\
\hline $\begin{array}{l}12-34, \mathrm{n}(\%) \\
35-58, \mathrm{n}(\%) \\
>58, \mathrm{n}(\%)\end{array}$ & $\begin{array}{l}20(28.6) \\
28(40.0) \\
22(31.4) \\
\end{array}$ & $\begin{array}{l}14(31.1 \%) \\
15(33.3 \%) \\
16(35.6 \%)\end{array}$ & $\begin{array}{l}29(33.0) \\
36(40.9) \\
23(26.1) \\
\end{array}$ & $\begin{array}{l}13(29.5) \\
19(43.2) \\
12(27.3) \\
\end{array}$ & \\
\hline
\end{tabular}

\section{Table 3.}

Polysomnographic measures in Caucasian and Asian menopausal women with high and low risk of sleep apnea

\begin{tabular}{|c|c|c|c|c|c|c|c|c|c|c|c|c|c|}
\hline \multirow{2}{*}{ Variable } & \multicolumn{6}{|c|}{ Caucasian women $\quad(n=115)$} & \multicolumn{6}{|c|}{ Asian women $(n=132)$} & \multirow{2}{*}{$\begin{array}{l}P \text {-value } \\
\mathrm{P}<0.05\end{array}$} \\
\hline & \multicolumn{2}{|c|}{\begin{tabular}{|l|} 
Perimenopausal \\
\end{tabular}} & $\begin{array}{c}(\mathrm{n}=56) \\
\mathrm{SD}- \\
\mathrm{n}=12\end{array}$ & \multicolumn{3}{|c|}{ Postmenopausal $(\mathrm{n}=59)$} & \multicolumn{3}{|c|}{ Perimenopausal $(\mathrm{n}=56)$} & \multicolumn{3}{|c|}{ Postmenopausal $(\mathrm{n}=76)$} & \\
\hline & \begin{tabular}{|l|}
$(1)$ \\
\end{tabular} & $(2)$ & (3) & \begin{tabular}{|l|}
$(4)$ \\
\end{tabular} & $(5)$ & $(6)$ & $(7)$ & \begin{tabular}{|l|}
$(8)$ \\
\end{tabular} & $(9)$ & $(10)$ & $(11)$ & $(12)$ & \\
\hline $\mathrm{SE}^{1, \%}$ & $71.74 \pm 8.4$ & $95.2 \pm 3.5$ & $96.2 \pm 2.2$ & $87.3 \pm 6.3$ & $90.5 \pm 2.7$ & $92.5 \pm 5.9$ & $75.2 \pm 5.3$ & $93.7 \pm 5.1$ & $96.3 \pm 5.1$ & $74.5 \pm 8.5$ & $90.3 \pm 4.73$ & $94.3 \pm 3.7$ & $\mathrm{P}_{1-2} \mathrm{P}_{1-3} \mathrm{P}_{4-5} \mathrm{P}_{4-6}$ \\
\hline $\mathrm{SL}^{2}, \min$ & $28.1 \pm 6.4$ & $16.2 \pm 3.7$ & $19.2 \pm 6.1$ & $26.3 \pm 3.3$ & $19.9 \pm 6.5$ & $22.3 \pm 18.2$ & $25.2 \pm 6.1$ & $19.5 \pm 2.7$ & $21.2 \pm 8.5$ & $19.1 \pm 5.8$ & $20.2 \pm 5.6$ & $21.8 \pm 5.4$ & \\
\hline \multicolumn{14}{|c|}{ Stage $(\%)$} \\
\hline 3 & $12.1 \pm 4.9$ & $19.1 \pm 6.4$ & $23.2 \pm 5.8$ & $12.2 \pm 5.4$ & $18.5 \pm 6.4$ & $19.4 \pm 3.8$ & $11.2 \pm 5.8$ & $18.1 \pm 5.4$ & $20.5 \pm 6.1$ & $10.1 \pm 5.2$ & $16.2 \pm 5.8$ & $18.5 \pm 61$ & \\
\hline REM & $19.8 \pm 5.1$ & $21.1 \pm 5.4$ & $20.1 \pm 5.6$ & $20.6 \pm 8.2$ & $21.6 \pm 9.3$ & $25.8 \pm 4.3$ & $16.1 \pm 5.9$ & $15.2 \pm 6.4$ & $16.8 \pm 5.4$ & $14.5 \pm 5.1$ & $22.8 \pm 5.3$ & $21.8 \pm 6.4$ & $\mathrm{P}_{4-10} \mathrm{P}_{10-11} \mathrm{P}_{10-12}$ \\
\hline $\begin{array}{l}\text { AGI }^{3}, \\
\text { event/ } \\
\text { hour }\end{array}$ & $13.2 \pm 2.4$ & $7.1 \pm 1.2$ & $6.2 \pm 0.5$ & $15.2 \pm 3.4$ & $8.5 \pm 0.5$ & $7.1 \pm 0.1$ & $18.2 \pm 3.8$ & $8.1 \pm 2.1$ & $6.4 \pm 4.1$ & $22.1 \pm 2.5$ & $9.2 \pm 4.1$ & $6.2 \pm 1.2$ & $\begin{array}{l}\mathrm{P}_{1-2} \mathrm{P}_{1-3} \mathrm{P}_{1-7} \mathrm{P}_{45} \\
\mathrm{P}_{4-6} \mathrm{P}_{4-10}\end{array}$ \\
\hline $\begin{array}{l}\mathrm{O}_{2} \\
\text { satura- } \\
\text { tion, } \\
(\%) \\
\end{array}$ & $90.1 \pm 3.1$ & $95.2 \pm 4.2$ & $96.4 \pm 3.5$ & $90.1 \pm 4.5$ & $93.3 \pm 0.5$ & $96.2 \pm 2.1$ & $91.1 \pm 3.8$ & $92.4 \pm 2.6$ & $92.1 \pm 2.1$ & $88.1 \pm 4.1$ & $89.1 \pm 3.1$ & $91.1 \pm 4.4$ & $\mathrm{P}_{4-10}$ \\
\hline
\end{tabular}

1. SE (leep efficiency) is a percentage computed as the total time spent asleep / the total amount of time spent in bed $\times 100$

2. SL (sleep latency) was calculated as time from beginning of the recording period to the first of 10 consecutive min of stage 2 or stage 3-4 sleep

${ }^{3}$. AGI - apnea-hypopnea index 
Results of our study showed differences in SD in Caucasian and Asian women. Although, the SWAN study involving White, African American and Chinese women has demonstrated that African women have the most severe night vasomotor reactions compared to Asian and White women. Moreover, the best sleep patterns have been shown in Asian women compared to Whites and African Americans, ${ }^{(26)}$ and our results confirmed this finding when comparing Asian and Caucasian women. Thus, Caucasian women, compared to Asians, have a high frequency of difficulty falling asleep and difficulties of morning awakening. However, Asian women have a high risk of SDB, both in the survey data and according to polysomnography. In this regard, we should emphasize a certain type of Asian physique with a short neck and trunk that was formed due to the centuries-old residence in a sharply continental climate with a hot summer to $38^{\circ} \mathrm{C}$ and frosty winters to $-50^{\circ} \mathrm{C}$.

There were no differences in sleep architecture between ethnic groups. It has been found that the representation of REM is greater in perimenopausal women than in postmenopausal ones, which can be explained by a change in sleep structure with age-decreasing delta-sleep and some compensatory increasing REM. However, some studies have demonstrated that there is a decreasing REM duration in normal aging. ${ }^{(7)}$ According to our results, it is possible that worsening of the vital status contributes to $\mathrm{SD}$, which is also reported in some other studies.

Results of our pilot study are not complete and need to be continued. However, for improving QL, it is necessary not only to pay attention to menopausal problems, but also to solve the sleep problems associated with various strategies, both age management and lifestyle, which have been stressed in a study by Woods et al. ${ }^{(27)}$ We believe that management strategies should be oriented towards ethnic features related to lifestyle and the type of response to aging.

\section{Conflict of interest}

The authors declare that they have no competing interests.

\section{References}

1. Madayeva IM, Kolesnikova LI, Petrova VA, Shevyrtalova ON, Sholokhov LF. [Changes in the processes of the lipid peroxidation and antioxidant defense system in patients with obstructive sleep apnea syndrome]. Pathological physiology and experimental medicine. 2009;(3):24-27. [Article in Russian].

2. Madayeva IM. Shevyrtalova ON, Madayev VV. Doksilamin's application at insomnia for patients with arterial hypertension. Consilium Medicum. 2009;(9):69-72.

3. Avis NE, Stellato R, Crawford S, Bromberger J, Ganz P, Cain V, Kagawa-Singer M. Is there a menopausal syndrome? Menopausal status and symptoms across racial/ethnic groups. Soc Sci Med. 2001;52(3):345-56.

4. Shaver JL.Women and sleep. Nurs Clin North Am.2002; 37(4):707-18.

5. Im EO. The Midlife Women's Symptom Index (MSI). Health Care Women Int. 2006;27(3):268-87.
6. Minarik PA. Sleep disturbance in midlife women. J Obstet Gynecol Neonatal Nurs. 2009;38(3):333-43. doi: 10.1111/j.1552-6909.2009.01031.x.

7. Kravitz HM, Joffe H. Sleep during the perimenopause: a SWAN story. Obstet Gynecol Clin North Am. 2011;38(3):56786. doi: 10.1016/j.ogc.2011.06.002.

8. Kravitz HM, Zhao X, Bromberger JT, Gold EB, Hall MH, Matthews KA, Sowers MR. Sleep disturbance during the menopausal transition in a multi-ethnic community sample of women. Sleep. 2008;31(7):979-90.

9. Durrence HH, Lichstein KL. The sleep of African Americans: a comparative review. Behav Sleep Med. 2006;4(1):29-44.

10. Hall MH, Matthews KA, Kravitz HM, Gold EB, Buysse DJ, Bromberger JT, et al. Race and financial strain are independent correlates of sleep in mid-life women: The SWAN Sleep Study. Sleep. 2009;32(1):73-82.

11. Mezick EJ, Matthews KA, Hall M, Strollo PJ Jr, Buysse DJ, Kamarck TW, et al. Influence of race and socioeconomic status on sleep: Pittsburgh Sleep SCORE Project. Psychosom Med. 2008; 70(4):410-6. doi: 10.1097/PSY.0b013e31816fdf21.

12. Ramos AR, Wohlgemuth WK, Dong C, Gardener H, Wright CB, Boden-Albala B, et al. Race-ethnic differences of sleep symptoms in an elderly multi-ethnic cohort: the Northern Manhattan Study. Neuroepidemiology. 2011;37(34):210-5. doi: 10.1159/000334315.

13. Tan A, Cheung YY, Yin J, Lim WY, Tan LWL, Lee CH. Prevalence of sleep-disorderedbreathing in a multiethnic Asian population in Singapore: A community-based study. Respirology. 2016;21(5):943-50. doi: 10.1111/resp.12747.

14. Netzer NC, Stoohs RA, Netzer CM, Clark K, Strohl KP. Using the Berlin Questionnaire to identify patients at risk for the sleep apnea syndrome. Ann Intern Med. 1999;131(7):485-91.

15. Fietze I, Penzel T, Alonderis A, Barbe F, Bonsignore MR, Calverly P, et al. COST Action B26 Group. Management of obstructive sleep apnea in Europe. Sleep Med. 2011;12(2):1907. doi: 10.1016/j.sleep.2010.10.003.

16. Margallo VS, Muxfeldt ES, Guimaraes GM, Salles GF. Diagnostic accuracy of the Berlin questionnaire in detecting obstructive sleep apnea in patients with resistant hypertension. J Hypertens. 2014; 32(10):2030-6; discussion 2037. doi: 10.1097/HJH.0000000000000297.

17. American Academy of Sleep Medicine Task Force. Sleeprelated breathing disorders in adults: Recommendations for syndrome definition and measurement techniques in clinical research. The Report of an American Academy of Sleep Medicine Task Force. Sleep. 1999;22(5):667-89.

18. Bixler EO, Vgontzas AN, Lin HM, Ten Have T, Rein J, Vela-Bueno A, Kales A. Prevalence of sleep-disordered breathing in women. Am J Respir Crit Care Med. 2001;163(3 Pt 1):608-13.

19. Montplaisir J, Lorrain J, Denesle R, Petit D. Sleep in menopause: differential effects of two forms of hormone replacement therapy. Menopause. 2001;8(1):10-6.

20. Netzer NC, Eliasson AH, Strohl KP. Women with sleep apnea have lower levels of sex hormones. Sleep Breath. 2003;7(1):25-9.

21. Sowers MF, Zheng H, Kravitz HM, Matthews K, Bromberger JT, Gold EB, et al. Sex steroid hormone profiles are related to sleep measures from polysomnography and the Pittsburgh Sleep Quality Index. Sleep. 2008;31(10):1339-49.

22. Randolph JF Jr, Sowers M, Gold EB, Mohr BA, Luborsky J, Santoro N, et al. Reproductive hormones in the early menopausal 
transition: relationship to ethnicity, body size, and menopausal status. J Clin Endocrinol Metab. 2003;88(4):1516-22.

23. Hall MH, Matthews KA, Kravitz HM, Gold EB, Buysse DJ, Bromberger JT, et al. Race and financial strain are independent correlates of sleep in mid-life women: the SWAN sleep study. Sleep. 2009;32(1):73-82.

24. Im EO, Lee B, Chee W, Brown A, Dormire S. Menopausal symptoms among four major ethnic groups in the United States. West J Nurs Res. 2010; 32(4):540-65. doi: $10.1177 / 0193945909354343$.

25. Richard-Davis G, Wellons M. Racial and ethnic differences in the physiology and clinical symptoms of menopause. Semin Reprod Med. 2013;31(5):380-6. doi:10.1055/s-0033-1348897.

26. Kravitz HM, Avery E, Sowers M, Bromberger JT, Owens JF, Matthews KA, et al. Relationships between menopausal and mood symptoms and EEG sleep measures in a multiethnic sample of middle-aged women: the SWAN sleep study. Sleep. 2011;34(9):1221-32. doi: 10.5665/SLEEP.1244.

27. Woods NF, Mitchell ES. Sleep symptoms during the menopausal transition and early postmenopause: observations from the Seattle Midlife Women's Health Study. Sleep. 2010;33(4):539-49. 